\title{
Mucin-poor and aggressive mucinous tubular and spindle cell carcinoma of the kidney: Two case reports
}

\author{
SHIRO UCHIDA $^{1}$, KOYU SUZUKI ${ }^{1}$, MIEKO UNO ${ }^{1}$, FUMI NOZAKI $^{1}$, CHIH-PING LI $^{2}$, ERIKO ABE ${ }^{1}$, \\ TERUO YAMAUCHI ${ }^{3}$, SAYA HORIUCHI ${ }^{4}$, MINOBU KAMO ${ }^{4}$, KAZUNORI HATTORI $^{5}$ and YOJI NAGASHIMA ${ }^{6}$ \\ ${ }^{1}$ Department of Diagnostic Pathology, St. Luke's International Hospital, Tokyo 104-8560; ${ }^{2}$ Department of Pathology, \\ Saitama Medical University, Saitama; ${ }^{3}$ Department of Internal Medicine, Division of Medical Oncology; \\ Departments of ${ }^{4}$ Radiology and ${ }^{5}$ Urology, St. Luke's International Hospital; ${ }^{6}$ Department \\ of Surgical Pathology, Tokyo Women's Medical University, Tokyo 116-8567, Japan
}

Received May 26, 2017; Accepted August 28, 2017

DOI: $10.3892 / \mathrm{mco} .2017 .1400$

\begin{abstract}
Mucinous tubular and spindle cell carcinoma (MTSCC) is a relatively rare renal epithelial neoplasm. Although MTSCC is considered to be a low-grade and indolent neoplasm, aggressive cases have been recently reported. The present study discussed two additional cases of high-grade MTSCC causing multiple distant metastases with a fatal course. In case 1, a 71-year-old patient presented with hematuria and pyuria. Computed tomography (CT) scan of the right kidney revealed a mass lesion, for which partial nephrectomy was performed. However, a follow-up CT imaging revealed distant metastases in the liver, the paraaortic lymph nodes and the bone. Despite molecular targeted therapy and irradiation, the patient succumbed due to tumor progression. In case 2, a 64-year-old patient presented with an incidentally identified mass lesion in the right kidney. A laparoscopic nephrectomy was performed, and a follow-up CT imaging revealed metastases in the skin and lungs. The cytology of pleural effusion revealed pleuritis carcinomatosa. Histologically, both cases were diagnosed as mucin-poor MTSCC with high-grade transformation, which comprised uniform tumor cells primarily forming slender tubules. The tumors contained low- and high-grade regions. In addition, venous invasion and necrosis were observed. The tumor cells also demonstrated increased Ki-67 labeling indices and cellular tumor antigen p53 (p53) nuclear accumulation. High-grade transformation, large tumor size, necrosis, venous invasion, high Ki-67 labeling index and p53 nuclear accumulation are generally predictive findings for aggressive behavior of malignant tumors. In the current report, it was emphasized that MTSCC possesses a wide spectrum
\end{abstract}

Correspondence to: Dr Shiro Uchida, Department of Diagnostic Pathology, St. Luke's International Hospital, 9-1 Akashi-cho, Chuo-ku, Tokyo 104-8560, Japan

E-mail: shiuchi@luke.ac.jp

Key words: kidney, mucinous tubular and spindle cell carcinoma, mucin-poor type, high-grade transformation, distant metastasis of clinicopathological features. Thus, careful postoperative investigation is required for MTSCC with high-grade elements due to its aggressive nature.

\section{Introduction}

Mucinous tubular and spindle cell carcinoma (MTSCC) is a rare subtype of renal cell carcinoma (RCC) introduced in the World Health Organization (WHO) classification system in 2004 (1) and included in the recent version of 2016 (2). Based on clinical characteristics, MTSCC predominantly occurs in middle-aged to elderly women (1:4 male-to-female ratio) $(3,4)$. At present, fewer than 100 cases of MTSCC have been reported according to a recent review (5). MTSCC characteristically comprises elongated tubules lined by low cuboidal epithelium and fascicles of spindle cells with a stroma containing mucinous substance (4). According to previous reports, MTSCC is subclassified into 2 histological types: classic and mucin-poor (6,7). Initially, MTSCC was considered to be derived from the distal nephron $(8,9)$. However, recent examinations revealed significant morphological and immunohistochemical overlaps between MTSCC and papillary renal cell carcinoma (PRCC); the latter possesses characteristics similar to proximal tubular epithelia. The cellular origin of MTSCC, thus, remains to be elucidated (10).

Although MTSCC has been described as a low-grade and relatively indolent tumor in the WHO2004 classification, there are several case reports on aggressive MTSCC, showing high-grade transformation (11-14). In the WHO 2016 classification, the description, presented in 2004, that the MTSCC version is indolent has been eliminated. In the present study, we report 2 cases of aggressive MTSCCs. To understand the exact clinicopathological characteristics of MTSCC, accumulation and comparison of aggressive and indolent cases are required.

\section{Case reports}

\section{Clinical results}

Case 1. A 71-year-old male patient who presented with hematuria and pyuria was admitted to our hospital. A computed tomography (CT) scan revealed a mass lesion, measuring 
$30 \mathrm{~mm}$ in diameter, in the lower pole of the right kidney (Fig. 1). Accordingly, partial nephrectomy was performed. One month later, follow-up imaging revealed multiple metastatic lesions in the abdominal paraaortic lymph nodes, pleura, and bones (ribs and pubic bone); the left lung; and in segment 4 of the liver. Although sunitinib, temsirolimus, and axitinib were serially administrated along with palliative radiotherapy to the left rib for pain control, therapeutic effects were limited and an adverse effect, interstitial pneumonia, developed. Finally, the patient died of respiratory failure due to the progression of the disease, 2 years after the surgery. Autopsy was not performed.

Case 2. A 64-year-old male patient incidentally presented a mass lesion in the upper pole of the right kidney, detected by an abdominal CT scan performed during a routine health checkup (Fig. 2). The patient underwent radical nephrectomy with a clinical diagnosis of RCC. Six months later, the tumor metastasized to the lungs and pleurae with effusion. Despite additional chemotherapy, 9 months after the surgery, the patient died of progressive disease and acute respiratory failure. Autopsy was not performed.

General. Surgically resected specimens of the 2 cases were immediately fixed in $10 \%$ buffered formalin and were embedded in paraffin. Paraffin sections $(4 \mu \mathrm{m})$ were subjected to histopathological staining. In addition, immunohistochemistry was performed by standard methods using the antibodies listed in Table I.

\section{Pathological findings and immunohistochemistry}

Case 1 . The resected kidney contained a poorly circumscribed tumor extending into the medulla. The tumor was tan-yellow to white and firm in cut surface, measuring $3.2 \times 2.2 \times 2.2 \mathrm{~cm}$ in size.

Microscopically, the tumor comprised slender and elongated tubulopapillary structure lined by cuboidal epithelial cells and fascicles of spindle cells. The tumor cells were small and uniform with round and spindle-shaped nuclei, containing fine chromatin and inconspicuous nucleoli (Fig. 3). The cytoplasm was pale to weakly eosinophilic. Depletion in extracellular mucinous material was identified. In addition, the tumor exhibited occasional foci of high-grade transformation, solid nest growth, and sheet-like growth pattern (Fig. 4). Nuclei with a higher grade contained prominent nucleoli. Precisely, the nuclear grade of the tumor was classified as Fuhrman grade 3 . The tumor showed vascular invasion, but the surgical margin was negative. However, necrosis and hemorrhage areas were not recognized.

By immunohistochemistry, the tumor cells were positive for $\alpha$-methyl acyl CoA racemase (AMACR), E-cadherin, and CD10, CD15 and EMA were focally positive. However, the tumor cells were negative for high molecular weight CK (34bE12), CK7, Vimenin, and c-kit. In the conventional area, the Ki-67 labeling index was 7\%, and the nuclear accumulation of p53 was focally observed. In the high-grade area, the tumor cells demonstrated an identical immunohistochemical reaction. However, the labeling Ki-67 labeling index was 34\%, and the p53 nuclear accumulation was markedly increased.

Case 2. The resected kidney contained a tumor in the upper pole, measuring $8.0 \times 8.0 \times 2.5 \mathrm{~cm}$. The tumor showed an

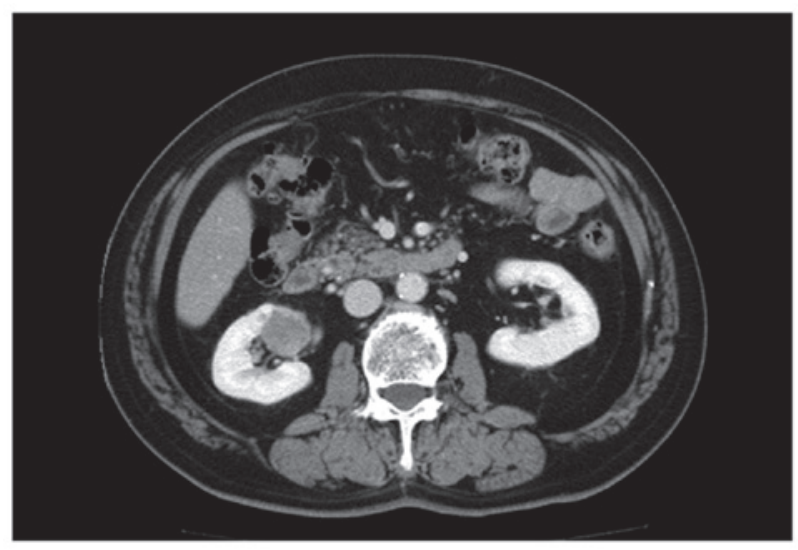

Figure 1. Case 1: Abdominal CT scans show a solid, enhancing mass in the right kidney.

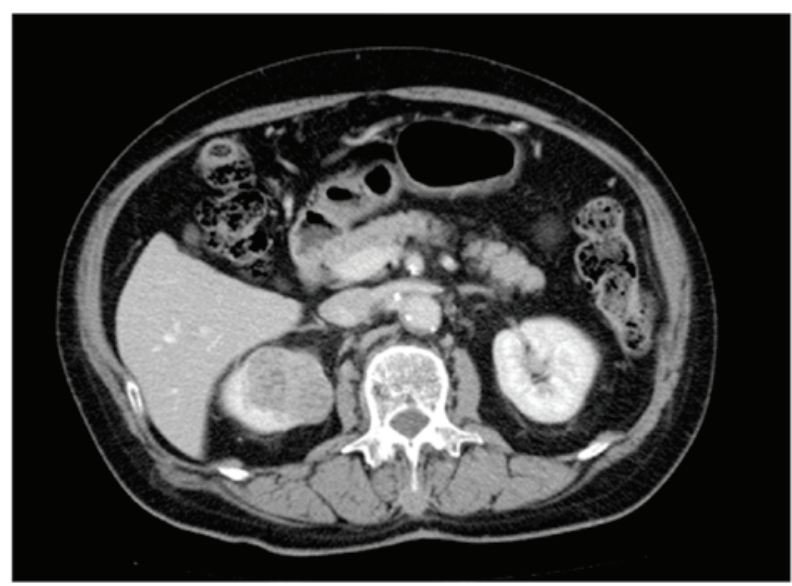

Figure 2. Case 2: CT scans of the abdomen show an exophytic, solid, enhancing mass extending from the superior pole of the right kidney.

ill-defined boundary with an invasive growth. The cut surface was solid, tan-yellow to white with hemorrhage and necrosis, and firm in consistence.

Although the predominant part of the tumor showed high-grade morphology, conventional MTSCC histology was occasionally identified (Fig. 5). The tumor lacked mucinous substance in the stroma. The majority of the tumor presented high nuclear grade, classified as Fuhrman grade 3, showing solid growth nests, trabecular pattern, and sheet-like growth pattern (Fig. 6). An extensive hemorrhagic necrotic area and vascular invasion were identified.

Immunohistochemistry results showed that the tumor cells were positive for AMACR (Fig. 7) and focally positive for E-cadherin, CD10, CD15, EMA, and CK7 (Fig. 8). However, the tumor cells were negative for high molecular weight CK (clone 34ßE12), Vimentin and c-kit. In the conventional area, the Ki-67 labeling index was 7\% (Fig. 9), and the level of nuclear accumulation of p53 was low (Fig. 10). In the high-grade area, the $\mathrm{Ki}-67$ labeling index was $32 \%$ (Fig. 11), and a marked p53 nuclear accumulation (Fig. 12) was observed.

In the cytological specimens sampled from the pleural effusion, small clusters of atypical cells were observed, which 


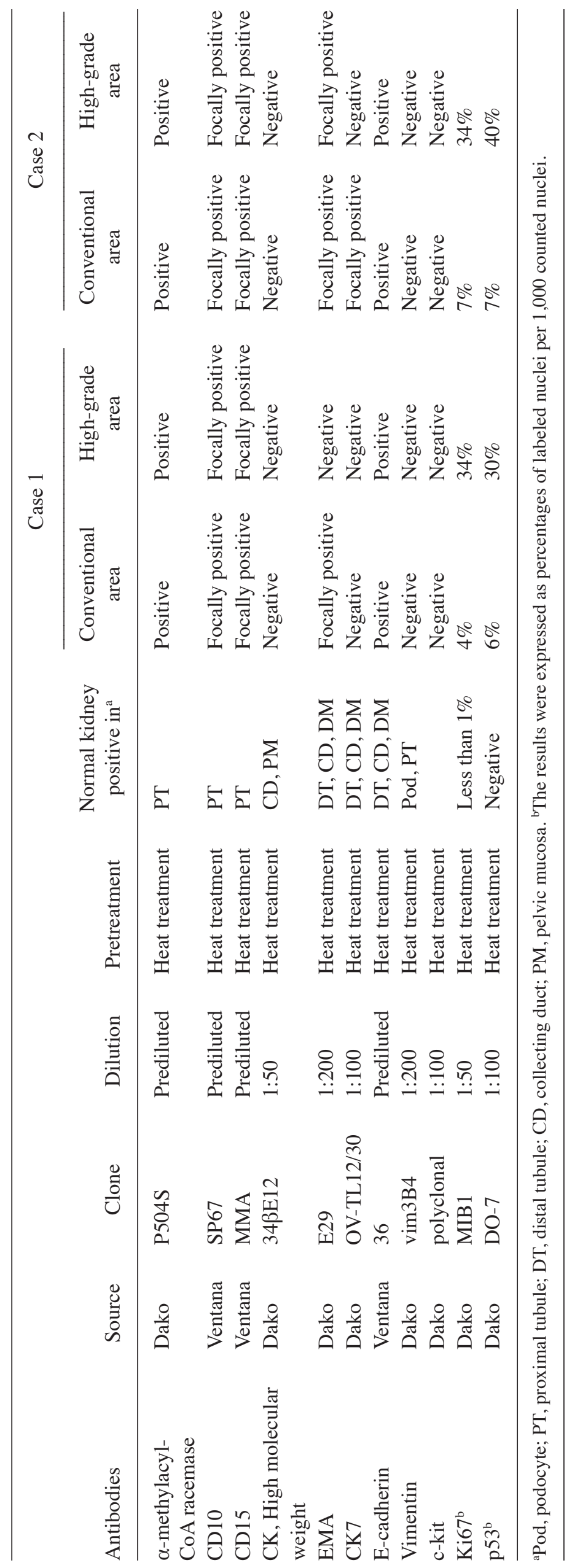




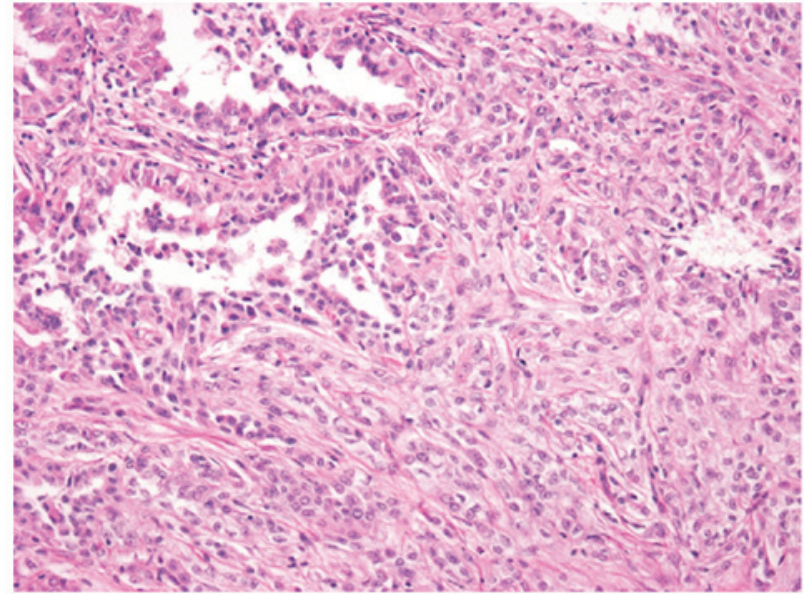

Figure 3. Conventional area (tumor showing tubular and cord-like pattern with cuboidal cells) (hematoxylin and eosin; magnification, x20).

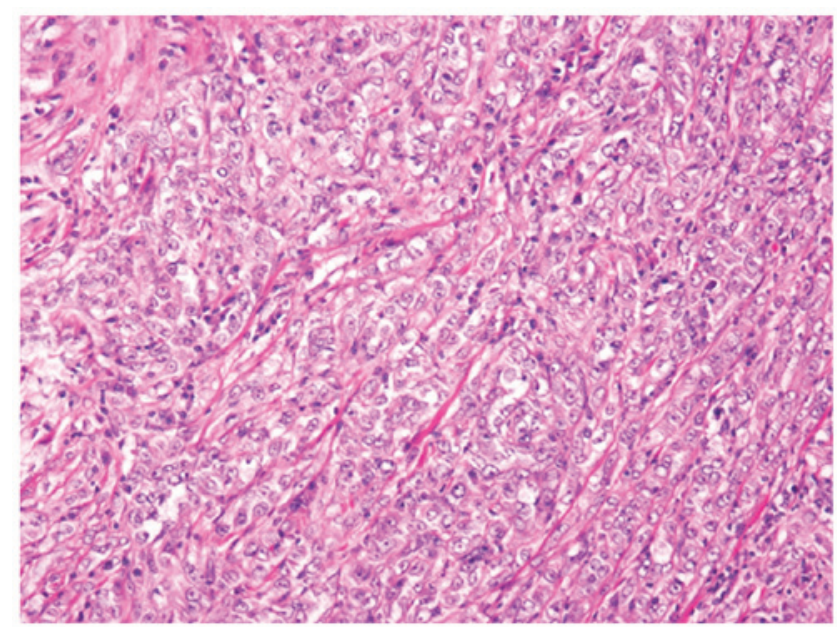

Figure 4. High-grade area (pleomorphic spindle cells with severe nuclear atypia) (hematoxylin and eosin; magnification, x20).

showed high nucleocytoplasmic ratio and hyperchromatic nuclei with nucleoli (Fig. 13).

\section{Discussion}

In 2004, MTSCC was introduced in the WHO classification as a relatively uncommon histological type of RCC. Initially, MTSCC was recognized as a low-grade collecting duct carcinoma (8); however, because of its significantly favorable prognosis, unlike that of collecting duct carcinoma, it was later recognized as an independent histological type (1). Recently, fatal cases of MTSCC with nodal and distant metastases have been reported (11-14). Therefore, in the 2016 WHO classification, description that MTSCC is of low grade has been deleted (2). A representative MTSCC is characterized by elongated tubular and spindle cell components with a mucinous stroma. Nevertheless, several MTSCCs have demonstrated unusual mucin-poor features (6) in addition to secondary progression, which is characterized by marked cytologic atypia, increased mitotic activity of tumor necrosis, and sarcomatoid changes (11-14). The cases presented in this report were considered 'mucin-poor' MTSCC

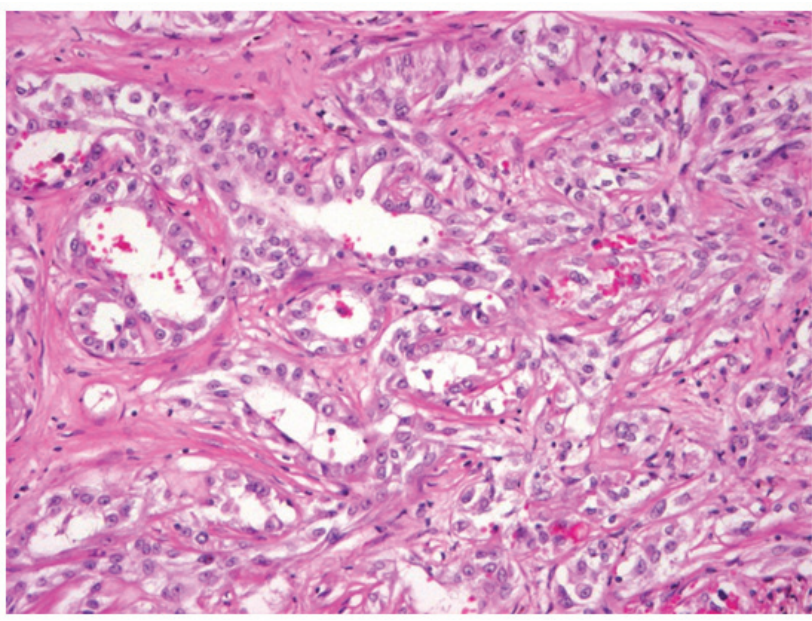

Figure 5. Conventional area (tumor showing elongated tubular pattern with cuboidal cells (hematoxylin and eosin; magnification, x20).

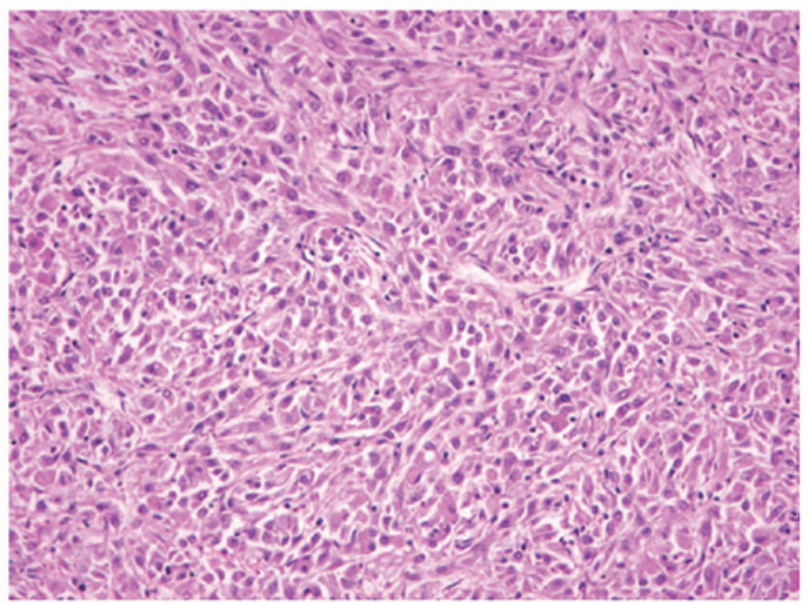

Figure 6. High-grade area (tumor cells forming solid nests with severe nuclear atypia (hematoxylin and eosin; magnification, x20).

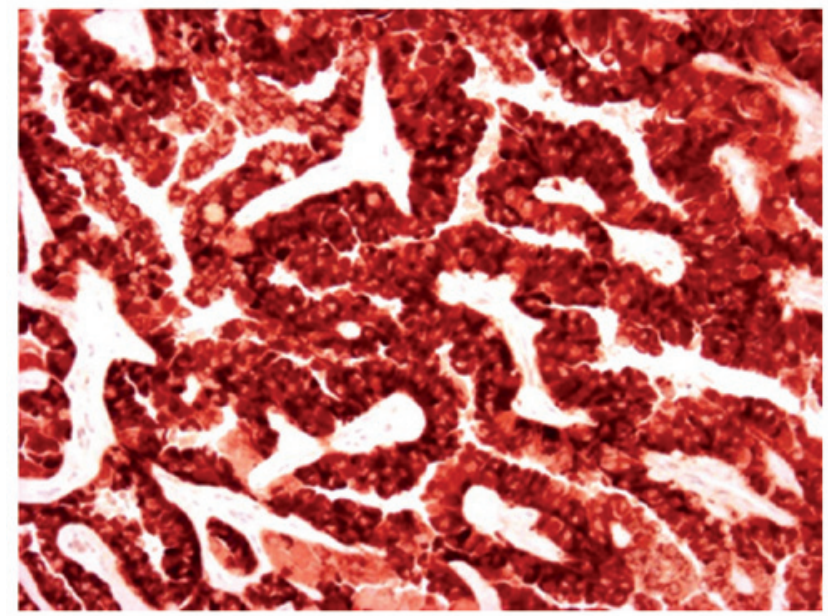

Figure 7. Tumor cells in the conventional area were diffusely immunoreactive for AMACR (magnification, x20). AMACR, $\alpha$-methyl acyl CoA racemase.

with high-grade transformation, and caused distant metastasis and tumor-associated death. 


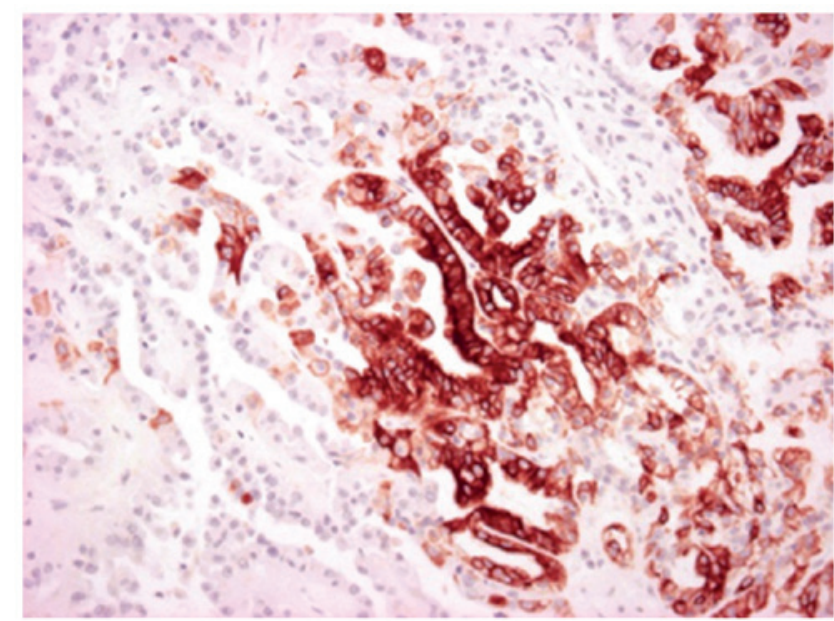

Figure 8. Tumor cells in the conventional area were focally positive for CK7 (magnification, $\mathrm{x} 20$ ).

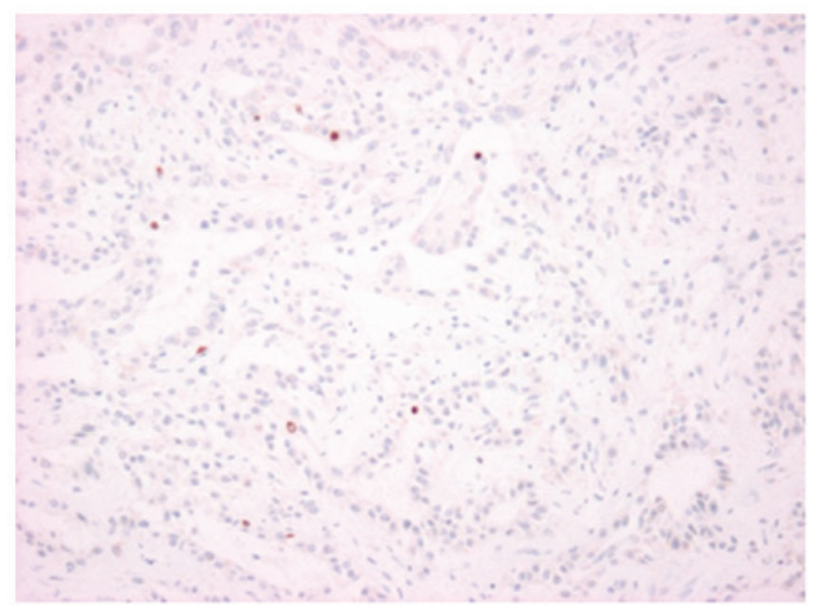

Figure 9. The conventional area showed a low expression of Ki-67 (magnification, $\mathrm{x} 20$ ).

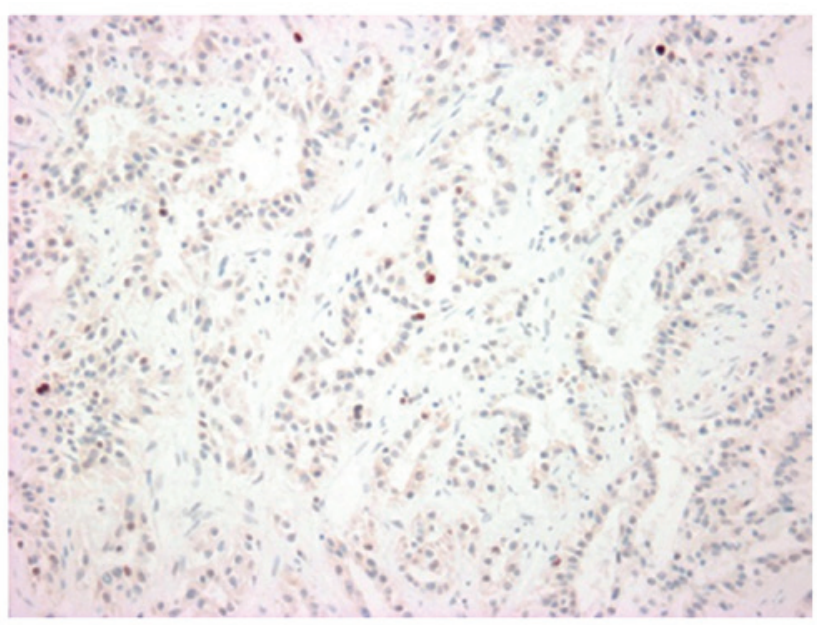

Figure 10. The conventional area showed low p53 nuclear accumulation (magnification, x20)

MTSCC has been reported to possess similar morphological and immunohistochemical characteristics of PRCC

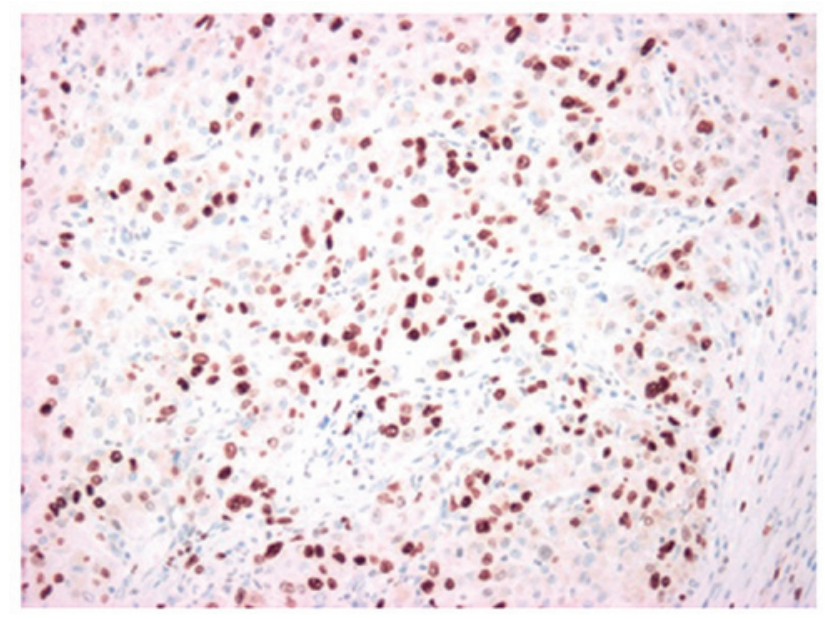

Figure 11. The high-grade area showed a high expression of Ki-67 (magnification, $\mathrm{x} 20$ ).

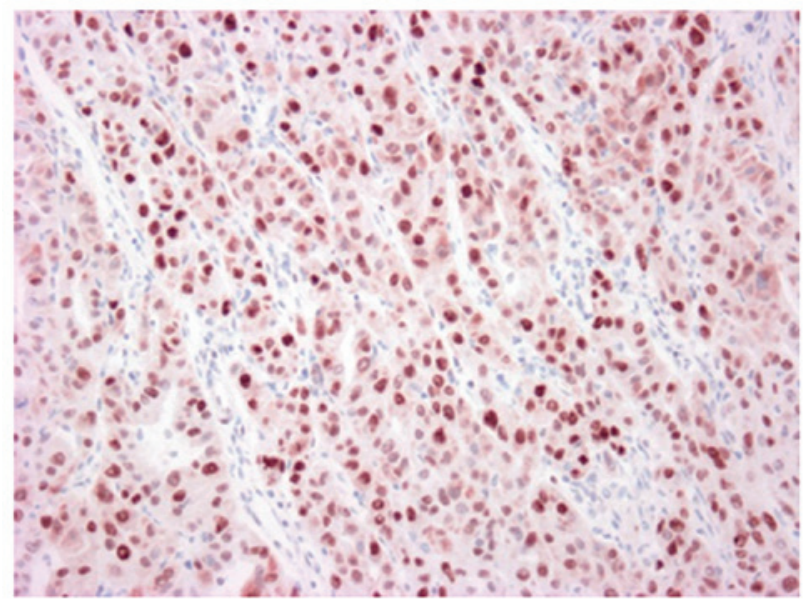

Figure 12. The high-grade area showed high p53 nuclear accumulation (magnification, $\mathrm{x} 20$ ).

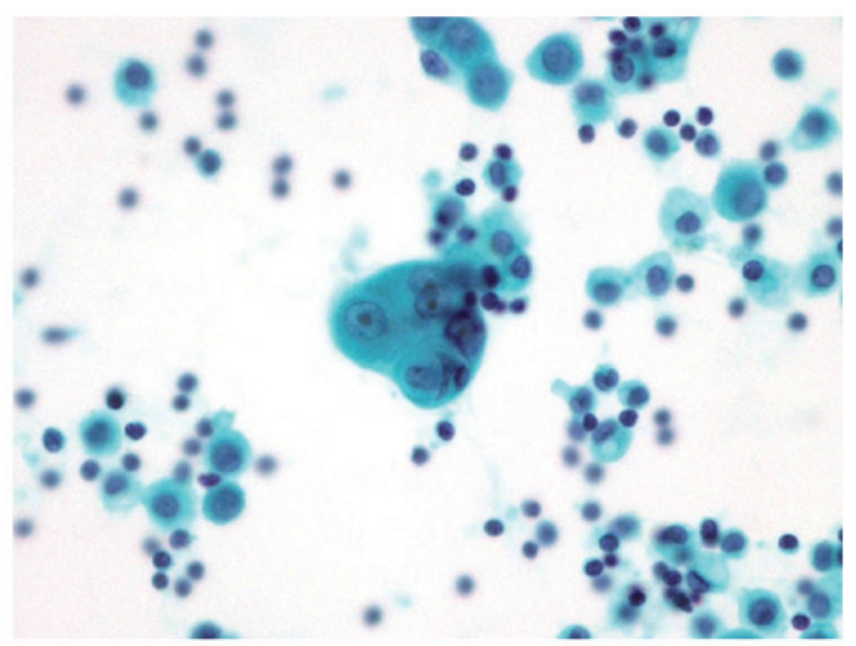

Figure 13. The cytology of pleural effusion by Papanicolaou staining showing the tumor cells in the inflammatory background (Papanicolaou: magnification, $\mathrm{x} 40$ ).

along with AMACR expression (6), which suggests that MTSCC may be a subtype of PRCC (15). Although AMACR 
expression hypothesizes that MTSCC demonstrates proximal nephron differentiation (10), to the best of our knowledge, histogenesis of MTSCC remains debatable. Our immunohistochemical study demonstrated that the tumor cells are positive for both a proximal nephron marker (AMACR) and distal nephron markers (E-cadherin and CK7). These results are similar to previous reports $(6,16)$. In addition, our immunohistochemical study demonstrated similar ecpression patterns between conventional areas and high-grade areas for AMACR, E-cadherin, CD10, CD15, EMA and CK7 and that the high-grade areas exhibited a high Ki-67 labeling index and p53 nuclear accumulation, which may be markers of high-grade transformation and predictors of poor prognoses in MTSCC. It is suggested that two hypotheses exist for high-grade transformation. While one transformation is thought to occur from low-grade MTSCC, the second possibility is 'de novo' development of a high-grade tumor (14). In our cases, low-grade MTSCC and high-grade area were transient. In brief, we observed that the high-grade area occurred by secondary progression of low-grade MTSCC. Thus, it is necessary to clarify the mechanism related to secondary high-grade progression. In case 2 , the cytological examination of pleural effusion revealed pleuritis carcinomatosa, and the patient died 9 months after surgery. Only one report has reported on pleural invasion; in that report, the patient died 1 month after surgery for acute respiratory failure (14).

Apparently, most MTSCCs are successfully treated with radical surgical resection. However, for metastatic MTSCC, no authorized guideline is available at present (5). In a previous study, one case of metastatic MTSCC showing a response to sunitinib was identified (17). Although case 1 in the present study was treated with a molecular targeted therapy, including sunitinib, its effect was limited. Further studies are necessary to establish the systemic therapy guideline for metastatic MTSCC.

In conclusion, MTSCC sometimes displays high-grade transformation, including sarcomatoid change. Therefore, it is necessary to perform a careful postoperative investigation of MTSCC with high-grade transformation. Our study revealed that large tumor size, tumor necrosis, vascular invasion, immunohistochemical findings of p53 abnormal accumulation, and high Ki-67 labeling index provide predict for poor prognosis. Therefore, clinicians should pay attention to distantmetastasis and tumor-associated death. Indeed, MTSCC is now considered a broad-spectrum tumor group because it exhibits various histological patterns, immunophenotypes, and clinical prognoses. In addition, further studies are necessary to elucidate the biological behavior, malignant potential, and histogenesis of MTSCC.

\section{References}

1. Srigley J: Mucinous tubular and spindle cell carcinoma. In: Pathology and genetics of tumours of the urinary system and male genital organs. Eble JN, Sauter G, Epstein JI (eds.) IARC press, Lyon, France, pp40, 2004.
2. Kuroda N, Paner G and Srigley JR: Mucinous tubular and spindle cell carcinoma. In: Pathology and genetics of tumours of the urinary system and male genital organs. Holger Moch, Humphrey PA, Ulbright TM (eds.) IARC Press, Lyon, France, pp37, 2016.

3. Wu XR, Chen YH, Sha JJ, Zhao L, Huang JW, Bo JJ, Liu DM and Huang YR: Renal mucinous tubular and spindle cell carcinoma: A report of 8 cases and review of the literature. Diagn Pathol 8: 206, 2013 .

4. Srigley JR, Delahunt B, Eble JN, Egevad L, Epstein JI, Grignon D, Hes O, Moch H, Montironi R, Tickoo SK, et al: The international society of urological pathology (ISUP) vancouver classification of renal neoplasia. Am J Surg Pathol 37: 1469-1489, 2013.

5. Zhao M, He XL and Teng XD: Mucinous tubular and spindle cell renal cell carcinoma: A review of clinicopathologic aspects. Diagn Pathol 10: 168, 2015

6. Fine SW, Argani P, DeMarzo AM, Delahunt B, Sebo TJ, Reuter VE and Epstein JI: Expanding the histologic spectrum of mucinous tubular and spindle cell carcinoma of the kidney. Am J Surg Pathol 30: 1554-1560, 2006.

7. Farghaly H: Mucin poor mucinous tubular and spindle cell carcinoma of the kidney, with nonclassic morphologic variant of spindle cell predominance and psammomatous calcification. Ann Diagn Pathol 16: 59-62, 2012.

8. MacLennan GT, Farrow GM and Bostwick DG: Low-grade collecting duct carcinoma of the kidney: Report of 13 cases of low-grade mucinous tubulocystic renal carcinoma of possible collecting duct origin. Urology 50: 679-684, 1997.

9. Parwani AV, Husain AN, Epstein JI, Beckwith JB and Argani P: Low-grade myxoid renal epithelial neoplasms with distal nephron differentiation. Hum Pathol 32: 506-512, 2001.

10. Paner GP, Srigley JR, Radhakrishnan A, Cohen C, Skinnider BF, Tickoo SK, Young AN and Amin MB: Immunohistochemical analysis of mucinous tubular and spindle cell carcinoma and papillary renal cell carcinoma of the kidney: Significant immunophenotypic overlap warrants diagnostic caution. Am J Surg Pathol 30: 13-19, 2006.

11. Dhillon J, Amin MB, Selbs E, Turi GK, Paner GP and Reuter VE: Mucinous tubular and spindle cell carcinoma of the kidney with sarcomatoid change. Am J Surg Pathol 33: 44-49, 2009.

12. Simon RA, di Sant'agnese PA, Palapattu GS, Singer EA, Candelario GD, Huang J and Yao JL: Mucinous tubular and spindle cell carcinoma of the kidney with sarcomatoid differentiation. Int J Clin Exp Pathol 1: 180-184, 2008.

13. Pillay N, Ramdial PK, Cooper K and Batuule D: Mucinous tubular and spindle cell carcinoma with aggressive histomorphology-a sarcomatoid variant. Hum Pathol 39: 966-969, 2008.

14. Bulimbasic S, Ljubanovic D, Sima R, Michal M, Hes O, Kuroda N and Persec Z: Aggressive high-grade mucinous tubular and spindle cell carcinoma. Hum Pathol 40: 906-907, 2009.

15. Shen SS, Ro JY, Tamboli P, Truong LD, Zhai Q, Jung SJ, Tibbs RG, Ordonez NG and Ayala AG: Mucinous tubular and spindle cell carcinoma of kidney is probably a variant of papillary renal cell carcinoma with spindle cell features. Ann Diagn Pathol 11: 13-21, 2007.

16. Ferlicot S, Allory Y, Compérat E, Mege-Lechevalier F, Dimet S, Sibony M, Couturier J and Vieillefond A: Mucinous tubular and spindle cell carcinoma: A report of 15 cases and a review of the literature. Virchows Arch 447: 978-983, 2005.

17. Larkin J, Fisher R, Pickering L, Thway K, Livni N, Fisher C and Gore M: Metastatic mucinous tubular and spindle cell carcinoma of the kidney responding to sunitinib. J Clin Oncol 28: e539-e540, 2010. 